Article

\title{
Theater against Borders: 'Miunikh-Damaskus'-A Case Study in Solidarity
}

\author{
Ruba Totah ${ }^{1, *}$ and Krystel Khoury ${ }^{2, *}$ \\ 1 Institute of Education, Johannes Gutenberg University Mainz, 55116 Mainz, Germany \\ 2 Laboratoire AcTé, Université Clermont Auvergne, 63000 Clermont-Ferrand, France \\ * Correspondence: rubatotah88@gmail.com (R.T.); Krystelkhoury83@gmail.com (K.K.)
}

Received: 28 September 2018; Accepted: 19 November 2018; Published: 27 November 2018

\begin{abstract}
In 2017, the City Theater of Munich engaged with a policy of diversity, and decided to include Syrian artists and create the Open Border Ensemble. A German and Syrian refugee and non-refugee cast produced the first performance, "Miunikh-Damaskus: Stories of one city" (May 2018). This mobile play aimed at minimizing stereotypes and deconstructing essentialist cultural identity prejudices. The paper examines how, in this case study, multilayered artistic strategies and relational dynamics came together to implement a 'third space'. It addresses the challenges and implications of such theater endeavors regarding solidarity and the representation of the figure of the artists within the realm of the migration and refugee discourse.
\end{abstract}

Keywords: third space; solidarity; postmigrant theater; representation; improvisation; translation; refugee crisis; cultural policies; relational dynamics; creative process

\section{Introduction}

In 2015, the German Federal Government opened its doors to an inflow of refugees after it agreed on a pan-European treaty (Dublin III agreement) aiming for equal acceptance of asylum seekers by the state members of the European Union. A mass movement of people seeking refuge, mainly from war-torn countries such as Syria, Iraq, and Afghanistan, reached Germany. With a clear political discourse emphasizing on sharing a 'welcome culture' (Wilkommenspolitik) and activating a policy of integration ${ }^{1}$ (Integrationspolitik), the Federal German Government made evident efforts to respond to ethical duties towards refugees, a fact that triggered, in return, critical philosophical public debates on hostility, hospitality, and their limitations (Funk 2016; Jäckle and König 2017). The massive influx of refugees presented a significant social challenge. One way of answering this challenge was to adopt a policy of cultural participation involving local authorities, cultural institutions, as well as independent artists. Artistic activism urged practices of cultural participation. Thus, cities such as Dresden, Göttingen, Hamburg, Mülheim, Berlin, and Munich implemented diverse and numerous artistic as well as sociocultural projects, whether as associative or institutional initiatives ${ }^{2}$. Those projects aimed at bridging people from different backgrounds and stimulating more interaction through art and cultural practices with the people who just arrived. However, a significant shift in policy-making

1 As stated in the Culture and Media Policy of the German Federal Government 2016: "Our society is being increasingly shaped by migration. Cultural participation is a basic precondition for migrants to be able to understand their new surroundings and to be understood by those around them. That is because cultural participation means social participation. And cultural education can play an important role when it comes to boosting cohesion in a heterogeneous, ethnically diverse society".

2 See: https://www.nachtkritik.de/index.php?option=com_content\&view=article\&id=11497:immer-mehr-theaterengagieren-sich-fuer-fluechtlinge\&catid=1513:portraet-profil-die-neuen-deutschen\&Itemid=85. 
occurred when in March 2016 some EU countries decided to close their borders. This shift was accompanied in Germany by the increasing popularity of right-wing political parties that made it to the Bundestag for the first time following the results of the 2017 elections. Those changes were going to have repercussions on the local cultural policy regarding the emergence, support, sustainability, and multiplication of artistic endeavors for or with people moving away from crisis areas and escaping conflict zones, as well as on discourses on solidarity and representation.

This article, in line with recent studies focusing on postmigrant theater (Spencer 2016; Komurcu 2016; Petersen and Schramm 2017; Wilmer 2018), is interested in theater experiences as solidarity endeavors where one surpasses the definition of the 'Other' based on geocultural difference. It investigates theater as a medium for discussing issues beyond migration and the 'Migrant' as the 'Other,' rather focusing on the 'living together' with what this entails as multiple dimensions. Current studies in theater and migration closely examine policies of inclusion in Europe (Sharifi 2016) and performative agency within the realm of refugee cultural and political activism (Bhimji 2015), as well as the variety of strategies, like verbatim and autobiographical documentary theater, for addressing problems of migration and the role of nation-states (Wilmer 2018). This case study wishes to discuss this topic from a socio-anthropological perspective based on a recent theater initiative: The Open Border Ensemble OBE at the Münchner Kammerspiele. It presents a microanalysis of a specific situation that took place during the rehearsing process of the performance "Miunikh-Damaskus: Stories of one City", focusing on the relational dynamics emerging out of this living experience and how it shapes a transcultural reality.

\section{Data and Method}

The analysis relies on participatory observation (Malinowski 1922; Cassell 2012; Charmaz 2014) as a method to collect first-hand qualitative data material. Indeed, the authors of this article, researchers Ruba Totah and Dr. Krystel Khoury, were also directly implicated in the abovementioned theater process: Khoury was the artistic director of the project and Totah was the translator and dramaturgy contributor to the theater production. Other than the ethnographic notes, penetrating insights, and highly contextual understanding brought by the three months of immersion, the corpus data included relevant printed and online communication material produced for the project. They used an empirical approach embedded in ground theory to examine one institutional artistic theater project The Open Border Ensemble initiated by The Münchner Kammerspiele in 2017, and a key moment from the creative process of its first theater production, Miunikh-Damaskus: Stories of One City, as a case study.

\section{Diverse Institutional Theater Practices}

Amidst the shifting political context in Germany in 2015, the art world, including the theater scene, demonstrated various solidarity statements to respond to policies of integration. These statements went hand in hand with initiatives led by artists and cultural operators from the German independent scene following state policies that encouraged cultural participation for integration. Major theater institutions in Germany, like Gorki Theater in Berlin, Schauspiel Hannover, Theater an der Ruhr in Mülheim, Deutsches Nationaltheater Weimar, and lately The Münchner Kammerspiele, opened their doors for theater projects with mainly Syrian and Syrian-Palestinian artists newly established in Germany-with the exception of Weimar and the AZDAR Theater ensemble from Afghanistan and Bremen, with the lately multinational Ensemble New Bremen ${ }^{3}$. Those theaters were trying to conceive midterm projects that aimed to go beyond usual one-shot productions where Syrian artists are working as 'guest artists'. Therefore, in continuation with the German theater tradition of 'Ensembles',

3 Steptext Company and Bremen Shakespeare Company: A cosmopolitan group of eight performers from Syria, Afghanistan, South Korea, Germany, Colombia, Togo, and Senegal to better reflect the diversity of the city. 
they implemented each a different model of theater inclusion depending on their artistic mandates and policies.

Starting in 2016, artists were called to form adjacent groups to those theaters' main ensembles. Maxim Gorki ${ }^{4}$ Theater created the Exil Ensemble. Following a form of theater refugee artist academy, it provided its members with German language and integration courses as well. Schauspiel Hannover ${ }^{5}$ initiated, in 2017, the Yalla Ensemble to "bring together, around the theater, people from different nationalities residing in Germany, mainly Hannover." Designed as an inclusive socioartistic project, it wished to give the opportunity to artists from Syria and Iraq to work with local youth from Hannover as regular theater workshops trainers and directors of youth theater plays. The Münchner Kammerspiele $^{6}$ founded The Open Border Ensemble as an experimental transnational collaborative project to resist borders and artistic isolation by calling artists living in Damascus to join the theater, with the aim to open a space for an exchange of expertise. In Mülheim, the group of artists Collective Ma'louba aimed to "establish an Arabic-speaking, international artists' collective $(\ldots)$ and develop various interdisciplinary projects which focus on producing Arab-speaking theater performance." While the theater institutions themselves artistically manage all of the above, this collective presented a more hierarchy-challenging structure, claiming a kind of autonomy from the Theater an der Ruhr ${ }^{7}$ who are only hosting and supporting in the administration of the collective. The analysis of how each theater introduces its ensemble on their website shows the specific and diverse motivations lying behind their creation. It also reveals that providing a space for an encounter is a common interest, despite the differences those theaters have in funding, audience development, and outreach strategies ${ }^{8}$. Those initiatives are not without facing some challenges.

If being part of those ensembles undoubtedly enables Syrian artists to recover their professional activity, the limited local or federal support questions their sustainability. Moreover, on an aesthetical level, operating under the social integration scheme with the 'refugee crisis' in the background, they have been producing - with only a few rare exceptions-narratives linked to war, forced exile, and escape experiences whether by, with, or for refugees. If those narratives complied at the beginning with the artists' needs to tell those stories and the German audience to hear them, this approach was soon revoked by many Syrian artists who started seeing in it stigmatization and labeling of the Syrian artist outside Syria as foremost a 'refugee artist' ${ }^{9}$. It carried assumptions and expectations towards their artistic production, conditioning their freedom of expression and creativity. From that perspective, it becomes interesting to take those ensembles as socio-anthropological laboratories to examine how they put at stake the construction of representations of newly arrived Syrians artists in Germany.

\section{The Open Border Ensemble: Theater against Borders}

Until the late nineties, when more practices started to open up to diversity, the German state theater was exclusive and closed to national interests, while the independent theater was more diverse. One of the main challenges of the German institutional theater has long been in its ability to create diversity within its structures and audiences, and in its accessibility by everyone (Wilmer 2018; Spencer 2016; Sharifi 2016). This challenge was to be explicitly addressed by the Münchner Kammerspiele new direction starting in 2015 with the arrival of Matthias Lilienthal. The theater decided to work since then with nonwestern directors from Lebanon, Iran, Japan, Greece, Mexico, and Argentina, to name a few, along with German directors. It invited those artists as associés

\footnotetext{
See: https://gorki.de/index.php/en/company/exile-ensemble.

See: https://www.schauspielhannover.de/index.php?f=07_seiten\&ID_Seite=285.

See: https://www.muenchner-kammerspiele.de/munich-welcome-theatre/open-border-ensemble.

See: http:/ / www.collective-malouba.de.

This is due to the histories of each theater institution, as well as social and political contexts of the regions they are based in. Interviews conducted with artists: Rania Mliehi (2017), Ayham Agha (2017), Shadi Ali (2017), in the framework of the PhD Research Experiences of Syrian and Palestinian Syrian Artists' with The Notion of Refuge by Ruba Totah.
} 
to produce performances for the theater repertoire. Moreover, a specific team Kammer4you was formed to work on audience development, organizing themed campuses for students, workshops for kids and teenagers, and presentations, after talks and symposiums. Opening up to a broader, younger, socially and culturally more diverse audience than before, the theater's artistic direction aimed at increasing audience curiosity with artistic productions that reflected more significantly on Munich's shifting demography and its culturally diverse social fabric.

As an engaged city theater, the new team of the Münchner Kammerspiele, unlike other German theaters, showed its concern towards the issue of refugees-their arrival, conditions, and new life in Munich-and was their first station in Germany. Indeed, soon after Germany's borders opened in September 2015, the theater organized The Open Border Congress within the frame of wider project ${ }^{10}$ called "Munich Welcome Theater" in October 2015. This congress gathered artists, scholars, activists, and "people who have come to Germany as refugees themselves or are simply interested in coping with the social challenges of worldwide migration movements". It called for a "society of the world that defends openness and diversity", a clear statement of solidarity. The theater later continued its active involvement with the issue of migration and exile by establishing the Welcome Café ${ }^{11}$ in April 2016. This format, away from an aesthetic positioning, leaned for more urgent social intervention. It made accessible one of the theater stages as a cultural place for local inhabitants and newcomers to meet, share, and access practical information and take part in cultural events, first weekly then monthly. The ongoing collective commitment expressed a common need to build up alternative narratives. In December 2016, this culminated in the production of the Open Border Ensemble Festival with Arabic-speaking artists and theater amateurs, featuring lectures, stage plays, films, and concerts providing momentum to the Café initiative. After the first rush and solidarity urgency, the theater decided out of this experience to give another configuration to The Open Border Ensemble project and develop it further by trying to shape it, based foremost on an aesthetic theatrical vision. The year 2017 was thus a preparatory year, leading to its implementation as such.

The asylum seekers' migration flow incited the theaters in Germany to work more towards inclusiveness and diversity and adopt transcultural approaches as a form of solidarity. In their article "Putting Flesh to the Bone: Looking for Solidarity in Diversity, Here and Now", Oosterlynck et al. (2016) observe that migration challenges solidarity resources, opens debates on new understanding of citizenship, and is classically based on interdependence, shared norms and values, struggle, and encounter. Thinking on a global level, the Münchner Kammerspiele questioned solidarity beyond the national scope, yet still in connection to it. Its interrogation revolved around how it can be in solidarity with other theater scenes, such as the Syrian one, how it can extend the solidarity scope and expand its borders while answering the urges of the German context, and which collaborative modality to trigger. The team perspective was embedded in postmigration discourses channeling the idea that the migration phenomena are a norm even though the heterogeneity they bring into society is still not reflected enough on German institutional theater stages. After auditions in Munich and Beirut, the theater invited Syrian performers-who had completed their theater studies at the High Institute of Dramatic Arts from Damascus, in Syria-to become part of The Open Border Ensemble (OBE). They were to take part in two theater productions, one of which was Miunikh-Damaskus: Stories of One City, directed by Munich-based German director Jessica Glause. This theater project was conceived for a mobile stage to tour in the open air in the suburbs of Munich, meeting new audiences, often unfamiliar with theater. Along the OBE members, this production included a Syrian-Palestinian guest female performer and a German actress from the Münchner Kammerspiele Ensemble. As such, the creative process became a place for encounter on more than one level, carrying the potential of activating transnational solidarity, shifting its understanding from "the bounded

10 This project is funded by Kulturstiftung des Bundes.

11 An initiative led by Anne Schulz and the Kammer4you team. https://www.muenchner-kammerspiele.de/en/staging/ welcome-cafe. 
territory of the nation state to the relationally constituted places where diversity is encountered and negotiated" (Oosterlynck et al. 2016).

\section{Miunikh-Damaskus: Stories of One City-A Case Study for Creating a 'Third Space'}

As its title denotes, Miunikh-Damaskus: Stories of One City is a storytelling theater play attempting to explore the possibilities of building a common space. This space, aiming to rethink forms of presentation and open new possibilities, can be considered as a 'third space', to borrow the expression of postmigrant theater scholars (Jeffers 2014; Joseph and Fink 1999; Sharifi 2016). In order to produce the theater piece, director Glause's creative approach used and combined some autobiographical elements provided by the performers as core material. Being the OBE's first production, it brought up the issue of Representation-what did the performers coming from Syria at that moment want to share as stories? Moreover, how and to what extent would these stories represent them? How do they want to position themselves in front of a mainstream German audience? The artistic team of this theatrical project included a director and her assistant, a dramaturg, a translator, a costume designer and her assistant, a music composer, a set designer, and five performers. Its creative process lasted three months, from February until April 2018.

In the following, we focus on a specific key situation we have observed during the creative process out of which we identify improvisation and translation as operating strategies in triggering relations between the director and the performers. We describe the relational dynamics that arose out of the creative process regarding agency and encounter-communications, behaviors, decisions, and self-disclosures. By agency, we refer here to the capability and ability of the performers to act for themselves, as well as about others, while having motivations and resources for the act (Kabeer 1999). We then analyze to what extent the relational dynamics contribute to transforming the theater lived experience into a transcultural reality, the third space.

\subsection{Description of a Key Situation: A Rehearsal Session}

The following situation took place a week after the beginning of the creative process, on the eighth day during an evening rehearsal. Usually, the team rehearsed in the morning and then in the evening on a four-hour slot. Afternoons were free so that the OBE actors could attend German language classes. The schedule was set on a daily basis, depending on the content of the rehearsal the director decided. Therefore, if most of the rehearsals were collective, some requested the presence of only two or three performers. The situation describes two distinctive moments. The first moment-Moment 1 -includes the director, the translator, and two performers: M., a German actress and K., a Syrian actor from the OBE. The second moment-Moment 2-includes all five performers K., H., F., S., and M., the translator, and the theater director.

\subsubsection{Moment 1}

$\mathrm{K}$. is late. While waiting for him to arrive, M. is on the phone outside the studio. K. arrives and goes in to wear the rehearsal outfit. M. is still downstairs on the phone. The director Glause is annoyed by this delay. She goes out and calls her: "We are starting!" The two performers gather. Glause takes out a paper with a 'nice text' written on it. The text (T), originally in Arabic, is a transcribed story K. has provided in a previous rehearsal. It tells about K.'s own perceptive relationship to the city of Damascus, triggered by the request of the director to talk about Damascus. K. takes a moment to recognize his text and to reconnect with the story told. He then comments: "I guess I am not convinced by it, maybe I should work on it again." The director replies that it could be modified later after they decide how it will be translated on stage by the other actors. She emphasizes that the final text will be given back to the actors and they can rework on it again together with the dramaturg in separate 
meetings ${ }^{12}$. Glause has a version of the text translated into English. She reads it to M. so that she can get familiar with its content.

Then, Glause explains the task to M.: K. will read the text in Arabic and M. has to tell the text in German, finding her translation technique. The translator sitting next to the director outside the stage will translate out loud the text in English to her. The task requires poli-attentivity, since the telling comprises focusing simultaneously on translating the text from English to German and finding ways to express it and make it understood by a non-Arabic speaking viewer. K.'s voice trembles each time he reads the text, a matter that Glause notices. M. shows much hesitation while trying to complete the task. The director regularly interrupts to give directives and comments on the accuracy of the translation and the performativity of the act of translation. At one point, M. pauses. She asks about the language to be used at the end during the performance. She says she feels more comfortable translating directly from Arabic to German without having the English translation. Glause shows that she understands her concern, but points out that the language used during rehearsals is English—understood by all—but agrees that this makes the situation confusing. They repeat without the intervention of the translator, but M. did not write down the English translation, so she struggles in finding her words every time they start over. In the end, Glause breaks in: "You know, two years ago I told a friend that I would like to work internationally, and now it seems uhhh, I'm lost in translation now." The team takes a break.

\subsubsection{Moment 2}

After the break, the other performers, N., F. and S. arrive. Glause explains the following: The Syrian performers will tell a story concerning themselves and related to Damascus back in $2008^{13}$. First, Glause asks K. to read his text (T) while others have to tell the story, over again, using their own styles and techniques. They can support, interrupt, retell, or reinterpret the text of K., but only using physical or vocal expression (like singing). K. starts reading his text in Arabic while M. translates it in German based on the English translation provided by the translator outside the stage, like in Moment 1. In parallel, the other three engage themselves in mime, gestures, and movements, expressing what $\mathrm{K}$. is saying without using uttered words. They try out this configuration three times. Each time, the director asks them not to imitate each other nor repeat the technique they have found, but to try to invent their own way of telling the story. N. uses pantomime, S. uses arms and pointed fingers to draw lines in the space, M. mimes with her hands while translating into German what she hears. F. is given a transparent paper and a pen with a projector. Whatever he inscribes will be projected on one side of the stage wall. He starts drawing.

After a sign from the director, N. starts with his story. He tells it in English. He tells how in 2008, he went around in Damascus with his friends following artists who came to visit the city, taking pictures with them. Years later, he showed it to his father, saying: "This is the Damascus that I like not the one now." Then, it is S.'s turn with the story. She tells, in Arabic, how she was preparing for the championship in Gymnastics in 2008. Suddenly, she pauses with tears in her eyes. She continues her story, weeping. Every time one of them starts telling his personal story, the others are asked to create images with their postures or signs of what is being told, while M.'s task with the help of the translator is to translate in German. While narrating, the performers pause for a moment to allow the translation process. They listen to the translations that are taking place in parallel.

It is F.'s turn. He decides to explain his drawing. A moment of tension arouses: His fellows, except M., show disagreement because he did not follow the director's instruction. Instead of using

12 It is after several discussions (collective and individual) and many dialogs between the performers, the director, the dramaturg, the artistic director of the OBE, and translator aiming at working on the style and sharpening the meanings transmitted that the director gave the performers a final manuscript. Some adaptations resulted from discussions during rehearsal breaks. A prolonged period of writing extended the creative process before a final manuscript was ready.

13 In 2008, Syria saw a prosperous moment in its history after the country started to open to the international market. The same year also marks the year of Damascus Arab Cultural Capital, with a vivid cultural program promoting local and international artistic events. This year was chosen by the director because one of the performers mentioned it in his improvisation. 
the transparent paper and the projector to translate the stories, he did an incomprehensible drawing. Following this, M. wishes to know what the drawing was about, so F. explains what it represents: The 'Amawi' (Umayyad) square, a landmark in Damascus, with its sword; and Barada river. However, what is inside the river is not fish. Fish has turned into bombs or eyes of dead people. K., who was supposed to have his story drawn by F., is drowning in the river. Moreover, his feet are held by a rope that is growing bigger and bigger, forming what F. calls 'the idea of Syria', 'a big one'.

\subsection{Strategies for Constructing a 'Third Space'}

\subsubsection{Improvisation}

In order to construct the performance, Glause's general creative process approach can be summed up as follows: First, she triggers the memory of the actors and actresses in order to bring out personal stories. She then selects the ones relevant to the storyline of the play by trying to combine, as much as possible, common stories from the daily life of the performers in order to find connections between the different places they come from. She then organizes one-to-one meetings for style assertion and discussion. This dialogical approach introduces a relationship between her and the actors away from a direct hierarchy. The themes tackled are related to the city, memories, dreams, and personal perceptions when changing spaces, and this is maybe what characterizes Miunikh-Damaskus stories compared to what Woolley (2017) identifies as the 'asylum story'. Unlike the depicted process by Woolley of constructing an 'asylum story' that results from a process of revisions practiced in a hierarchy by translators and administrative and legal representatives during hearing sessions, the stories of Miunikh-Damaskus move away from this narrative. They focus on offering new images and experiences of Damascene life that are rarely told by the mainstream media. This choice is also related to the fact that other than one performer who has a refugee status that shaped her relationship to the space, the others had just arrived to Munich to work as actors. The narrative was thus constructed around personal stories from a war zone area-which emphasized the transcultural aspect of this theater process. This environment comprises no legal decision maker in front of the narrator, yet relates the Syrian performers in Germany to the refugee crisis in general by the simple fact of being Syrian citizens. They become, like Cox would write, "authorized non-citizens" in the sense of citizens with temporally limited rights to move to and within nations.

This dialogical approach in constructing the narrative calls for a triangulation (Cox 2018) made by most verbatim ${ }^{14}$ theater "narrative, validation and innocence (morality of the human story)" in order to guarantee situating the story within a humanizing paradigm and to enable possibilities for imaginative audience engagement. The dialogical approach in the creative process aims at building up trust to achieve this triangulation and make the actors tell more stories easily during rehearsals. It facilitates sharing the stories that would become a creative resource for the performance. It also empowers the director in her leading role and maintains her authority in the triangulation and the formation of the story. It is only after this connection is made that she delivers back to the performers the material selected and reconfigured by her for dual or collective semidirected improvisation sessions.

The observed situation describes one of the rehearsal sessions characterized by a layering of improvisations. Indeed, it builds upon previous days of improvised material, but also creates new ones. Here, improvisation as a theater practice allows personal stories to emerge and be told for the first time as raw material. It also pushes the performers to find creative techniques to transmit those stories beyond language, including the use of drawing to construct other fictional stories inspired by the original personal story. Each actor discloses a personal story. By asking them to repeat the task, the director orients the performers to recreation and to enhance a new way of transmitting the

14 According to Cox, it is a subset of documentary theater devised wholly or in part from the words of real people and has oral testimony at its heart. Practitioners of the form often regards their work as intervening in the public record, offering new or alternative accounts of events (145). 
story of the other. While she does not play the role of the decision maker who seeks the discoverable truth, as Woolley (2017) calls the 'truth finder', she practiced her role to lead the invention of new means of connecting the stories of the performers together. Repeating opens to them the possibility to re-appropriate their story, disrupting the director's authority, and also to identify or at least to familiarize themselves with the stories of their fellows. However, the director's artistic directives, interposing regularly the flow of the improvisation session to keep up with the storyline, assert back her authority position.

In the interviews led with the performers during the project, K. perceives the use of improvisation as a tool to introduce oneself to the other and vice versa by experimenting with unusual methods. He says it encourages the creation of a comfort zone, opening up for self-experimentation and evaluation, surprise, and self-content. Additionally, unlike his previous professional experiences based on written plays, the improvisation session is led in this process by 'a supportive authority' that continually encourages new ways of expression. While F. sees in the improvisation sessions too much authority, it compromises his free space as an actor. However, he adds that those sessions call for activating practices of adaptation to overcome the challenge.

In Moment 1, the uttered sentence of K.: "I guess I am not convinced by it. Maybe I should work on it again," to which the director responds with "later", reveals a cognitive process encompassing the capability to act even if still concealed in the rhetoric. Indeed, the verb 'guess' indicates the awareness of the actor towards a certain reality, 'convinced' indicates a decision making, and 'work' indicates a possible action. It reveals a confrontation with himself. Similarly, for M., although her hesitation, pause, and questioning in the middle of the exercise denote a certain feeling of discomfort, she takes action by stating that she prefers not having the English translation, a matter that would put her in a struggling position afterward when rehearsing. Although the director justifies the process, she accepts the request of M. Later, in an interview, M. explains that within such a multilingual context and diversity in acting styles and cultural backgrounds, she believes using improvisation, in general, is a difficult experience. However, if it makes it more difficult to cope with the transcultural situation, it also challenges her to break out of her comfort zone and start a process of self-experimentation, activating her abilities to contribute to the needed collective aspect of this particular theater-making experience. In Moment 2, F. follows the task of using drawing while drifting from it at the same time: He does not translate his peer's story, but invents a new one which differentiates him from others, yet puts him in an isolated position regarding his peers who show disagreement. Additionally, while K. tells his story, others are encouraged to support or to interrupt by telling their stories. The actors mostly interrupt and, therefore, the stories do not develop collectively. This repeats when $\mathrm{M}$. stands against his peers' disagreement to share the story of F. They extend the confrontation with the self to include a confrontation with the other. It makes the other a constituent of the confronted self.

Other confrontations described in the interviews are related to external factors to this transcultural improvisation experience. K. says that he is not sure if his stories will be interesting for the audience being put on stage that way: Whether the decisions resulting from confrontations and negotiations he engaged in with peers and with the director to develop this performance will be meaningful to audience. Further, M. described that she needed peer-support from German actors in dealing with such a multicultural project. F. described a need to create imaginative spaces about the city of Munich which could have enriched his improvisations and minimized his alienation from the venues, the city, the audience, and the artistic decisions in the project.

Those confrontation moments can be called endurance-in-the-self moments that are expressed, whether before action (case of K.), or accompanied by action (case of M. and F.), or following the action. They are key instants illustrating processes of agency formation, allowing the performers to have the space to develop their self-image and negotiate it, showing their singularities. This deconstructs the attempt for any collective representation of the 'Syrian Artist'. By doing so, actors expose to the director and the group a subjective representation of themselves. They describe situations where the performers 
are actively engaged in the theater process of negotiating their position within the group. They are triggered by the main theater creative tool used throughout this creative process: Improvisation.

More than a creative tool, improvisation operates as a strategy through which the performers are able to position themselves as agents regarding the directive authority and peers. They can activate their agencies, their capacities as individuals to act independently, by expressing, changing, transposing, transforming, and extending stories and standpoints. Improvisation operates as a strategy to regulate the asymmetrical relational configurations (Simmel 1999) and the confrontations emerging between the performers and the director, which determine or limit their decisions as agents, as well as between the performers themselves as a heterogeneous group with different acting approaches and cultural backgrounds. It encourages what Woolley (2017) describes as the hybrid prose formation of stories which results from enhanced agencies in the processes of sharing their stories. It creates a 'third space', which is not the addition of the performers' spaces and the director's space, nor a binary oppositional representation of each, but another emerging space of ongoing tension and negotiation.

\subsubsection{Translation}

With a Syrian and German cast, the Miunikh-Damaskus creative process raised the issue of language. The director openly addressed this matter from the start as a challenge to be surpassed. Sentences such as "How do we manage language together?", "How to avoid misunderstandings?", "How to initiate a space to know each other?", "This will be important for our work, especially that there are three languages," "the most difficult thing is the language now," punctuated her introductory speech on the first day of rehearsals. In this transnational project, German, Arabic, and English - as the common working language-were used. Moreover, aware of the essential role translation plays as a precondition to the construction of any shared space and to facilitate the communication process, the theater direction appointed an interpreter. The interpreter fulfilled many functions, from direct translation to transcription to cultural mediation. She translated the conversations between the director and the performers. She also translated the directives of the director to the Syrian performers during the sessions and what they were improvising. To be able to select the parts she was interested in, the director used a recorder. The interpreter was also responsible for providing a written translation of the recorded selections to the director, who would bring those texts again to the working sessions. Those texts formed the written material based on which the performers would create a scene. Thus, translation comprised technically translating the communication around the artistic material that is mainly facilitating the communication between the director and the Syrian performers, as well as translating to English the content of the material improvised by the performers in Arabic.

In Moment 1, Glause brings a text (T) in its English and Arabic version, narrating a personal story of $\mathrm{K}$. that was recorded during a previous improvisation session. She gives as a task to M. to translate it to German while K. is reciting it in Arabic. Similarly, in Moment 2, she asks the other performers to physically translate the story of K. The session revolves around how to best translate K.'s text on stage using creative methods so that, later on, the German audience understands it. By giving this task to the performers, Glause not only put translation at the core of the communication process between the participants, but also literally put the translation process on stage as one of the main subjects of the theater piece itself. Indeed, to ask the actors to translate becomes a typical task in the following improvisation sessions. By adding layers of translation in the scene (Moment 2), the text goes through a continuous process of transformation of the meaning. The performers attempt to transmit, in their own language, the story of their peer told in another language (M.'s case). They improvise new ways of conveying its content (H. and S.'s case). Moreover, depending on the medium used (body, projector), each time they translated, they added a new layer of comprehension to the extent of creating a new story inspired by it (F.'s case). More than a communication tool, translation operates as a creative strategy in paving the way towards a third common space. 
Like improvisation, the use of this strategy also shaped the relational dynamics between the director and the performers in a challenging way. The fact of insisting on creating a multilingual theater play where the mother tongues of the participants are different was a way to acknowledge the cultural specificities against assimilation. It empowered their agencies. Although K. could speak English, he systematically chose Arabic in all improvisations. Although M. was not sure of what K. was saying, word-by-word in Arabic, she revoked the translation in English, wanting to improvise/translate directly in German. However, the director's recurrent interruptions were shifting back the power balances to gain her leading position again. A position constantly challenged by the fact of having to write a text with source material in a language she cannot understand (Arabic), translated in another language that is not her mother tongue (English) but that operates as a translanguage in such a plurilinguistic team. It is by making translation central to the creative process and maintaining a specific collectivity through a shared language that the director practiced her authority. She brought legitimacy to the stories within her play storyline by multiplying them with several languages and bringing a reiterated story opposed to what Woolley described as the 'asylum story' by maintaining aspects of 'home narratives'. Her concluding sentence in Moment 1, 'You know, two years ago I told a friend that I would like to work internationally, and now it seems uhhh, I'm lost in translation now,' reveals the ambivalent nature of translation. Translation enabled the construction of a transcultural space and opened up possibilities to unravel indeed, and sometimes to resolve conflicts arising from oral miscommunication and to go beyond differences, yet it reminds of the presence of those differences. This reminder kept the negotiations between actors and the directive authority ongoing.

In Moment 1, M. pauses the translation and steps out, requisitioning the efficiency of this tool within the creative act, especially that as much as this translation was facilitating the creative process, it was interrupting her creative agency as an actress. Learning the stories of her peers through this translation routine took place amidst recurrent interruptions. However, in the performance on stage, she became an agent of those stories. Translation stimulated self-confrontation moments for M., where she had to develop her role from being an actor into creating a new image of herself of becoming an actor-translator. Meanwhile, $\mathrm{K}$. is confused every time he reads the text and listens to its double translation (English and German). Hearing his own story again confronted him with it and with the director's creative process. Similarly to Moment 2, even if the voice of the translator in the rehearsal space tries to adapt emotionally to the improvised situation, it imposes a certain rhythm: The actors have to systematically stop and listen to the translation while improvising and confronting themselves to their own stories.

In addition, In Moment 2, interpersonal confrontations create situations of 'tremble', 'hesitance', 'pausing', and 'struggling', which influence the communication between actors by continually distorting the messages, emotions, and follow-up processes by the other actors while they create scenes. In Moment 1, M. continues to develop her translation skills without reference to the paper, even though she later describes how difficult the improvisation process was to her. Her resilience was confronting her with cultural difference and preparing her for another confrontation with the audience in the final performance. This confrontation included a new representation of herself as an actor-translator of a multicultural third space. Translation operates as a strategy that regenerates difference and stimulates new positions of performers as agents to constantly negotiate this difference. It enables them to activate their agencies as individuals to give meaning to the shared space of cultural difference negotiations, the 'third space'.

The microanalysis of the observed situation and the identification of the multilayered creative strategies in use demonstrate the mechanisms through which a transborder theater experience is built up, constantly shifting between drawing limits and then crossing limitations between the self and the others. Improvisation is about the creation and recreation of stories and situations, whereas translation is about communicating and connecting people and raising challenges, understandings, and ideas. They involve the self and the other. As such, they both function as strategies to transform the creative process into a third space as a relational experience. It is an experience of disorder and confusion 
where agents have to confront themselves simultaneously and encounter with others, reconsidering their habitual routines. It is within this relational tension that a transcultural reality unfolds. It starts being constructed as soon as the stories, outspoken and traveling across a geographical boundary, are shared, multiplied, and transformed. Throughout this process, the performers are urged to rethink, be more aware of what they present and represent, and contemplate to find motivations to redefine themselves in a new place that is in motion.

\section{Discussion}

\subsection{Third Space and Solidarity}

Relational dynamics discussed in the case study correspond to what is seen by Gelfand et al. (2006) as envisioning the self as in its relationship with the other, where negotiation of representation involves both the self and the other. The relational dynamics within this transcultural reality describe practicality on the interventions on the concept of the 'third space', which refer to a medium of new possibilities for translating cultural difference, maintaining plurality, and challenging the authoritative forms of control and challenging binaries (Joseph and Fink 1999; Sharifi 2016). The third space of OBE is constructed within the framework of the German theater institution solidarity with issues of migration and flight. While solidarity motivates establishing adjacent ensemble models, one main challenge to this solidarity approach is that ensembles, like OBE, are subject to conditional funding and limited duration. This conditions the migration phenomena to a limited temporary social determinant and limits the space for broader and larger solidarity. In an interview, Glause says: "I planned to discuss some issues about the project with the theater administration, but then I realized that this experience is happening only once, it's not happening again."(Glause 2018) This temporality of engaged practices challenges the sustainability of the concept of the 'here and now'. Temporality can refer to a 'utopian performative' (Dolan 2002) which creates a temporal space for critique, perspectives, difference, and a practice of the identity of the other through translation and improvisations to negotiate beliefs on the bases of these differences. It stimulates 'a structure of feelings' among actors and actresses as they engage in this temporal space. If solidarity is 'nurtured through the very practices people jointly engage in diverse places' in the here and how (Oosterlynck et al. 2016, p. 12), then temporality becomes essential to the theater as a practice of solidarity. The legal state of authorized noncitizenship and other states of 'unauthorized noncitizenships' (theater makers in exile whose transnational mobility is 'unauthorized') maintains an unsteady ground for joint human-paradigm based practices of solidarity (Cox 2018). The postmigrant theater scholarly efforts in Germany call for beyondness in critically and reflexively discussing migration in theater and the Open Border Ensemble presents its members within the scope of this beyondness. The above microanalysis proposes improvisation and translation as strategies to create a third space of beyondness, where moments of enduring-in-the-self are practiced in larger temporal and artistic scopes, and where solidarity is continuously constructed within theater relational dynamics.

The theater institutions solidarity statements, as well as the mechanisms of establishing the OBE and third space creation strategies, contribute to the Syrian, the artist, and the refugee-artist figures and representations in German society. In the research on solidarity in diversity, solidarities grow as people practice life experiences together in diverse places, relationally. Being citizens of specific legal entities could be overcome by finding innovative forms of solidarity elsewhere that consider the specific situation of the encountered practice and the time span when this encounter happened (Oosterlynck et al. 2016). Then, citizenship is defined by acts and interpersonal practices of diverse individuals, their representations, and their varying positions in the society sphere (Ibid., p. 13). This case study builds on this political and social perspective of solidarity by stressing that within a single encounter practice over a time span reside various representing mediums that are guided by the agency of individuals. 


\subsection{Third Space Strategies}

If improvisation is a strategy for a 'third space' that deals with creating, recreating, and negotiating stories and representations of the Syrian actors of the OBE, improvisation could become a strategy of the overall transnational experience of OBE members in Munich. Cultural participation of Syrian artists in this case study constitutes a nexus of their artistic activism and the disorder/reorder processes of their life routines. In addition to the negotiations they are involved in during the creative process, it includes the simplest personal behaviors that the artists coming to Germany had to reconsider as a consequence of their moving, for example, reorganizing life habits, and moving away from comfort zones: Changing sleep routines, excess sweating while sleep, dropping off phone calls routines and transport habits from and to the workplace. In addition to life habits, they experience an active reorganizing of work conditions and contracting processes, work permits, registration at the city departments, city infrastructural routines, weather conditions, language requirements, and content prepreparation.

Improvisation is explained by Montouri (2003) as the state when a decision is made to deviate from order, where the best thing to do is to improvise, knowing that there will be a return back to order at some point. Creating a third space can be considered the OBE members' negotiation, deviation medium, from a fixed understanding of the self. This medium is temporal, where encounters are extended and deepened to illuminate the cultural difference in the creative process before a new common understanding is derived or before the deviation ends. This extension may be prolonged until moments of evaluations, contemplation of individual representations are given enough space to occur, and where collective agencies are eventually forming to provide new meanings and new representations of cultural differences. This third space turns the deviant approach into a strategy, which opens possibilities for new representations, affiliations, and solidarity.

In addition to improvisation, the translation strategy contributes to the construction of relational dynamics among OBE members. In literature, the translation layers of the OBE fall into several styles but mainly relate to 'community interpreting', which almost all OBE members practiced in certain moments, and mainly resembles the actor-translator role of the German actor. Community interpretation as a practice of volunteers, untrained bilinguals, friends, and relatives is an active, communicative tool that involves face-to-face interaction and emphasizes the role of the translator as both a language and a social mediator (Baker and Saldanha 2009). This form of translation is mostly practiced in this case study by the German actress, who eventually transforms the third space into a community space, a social medium of interaction. As the translation strategy coincided with the improvisation process, it managed to create what Spivak (2009) calls an 'intimate act of reading' that closely attempts to comprehend the stories of participants, to realize the limits of the knowledge to translate them. As a strategy, it continuously uncovers confrontations of the self regarding what it realizes as a lack of knowledge about others. It ceases to be a technical activity, but a 'subject-constituting process' which constantly shuttles between interior and exterior, between self and other, between individual and collective (Bala 2014). Translation in Miunikh-Damaskus shuttles between the interior and the exterior, in the self and the other of its members, enabling a better understanding of emerging representations of artists. Doing so over a period of time, solidarity space aided by this medium of translation is no longer in finding common space between artists, but in the experiencing and learning of each other within a third space. Solidarity in the Miunikh-Damscus theatrical experience is thus stretched beyond common grounds to interpersonal practice over an extended period of time.

Author Contributions: For this article, conceptualization, methodology, writing —original draft preparation, writing-review and editing, investigation for Sections 3 and 4 are the work of both authors R.T. and K.K. Investigation for Sections 5 and 6, data validation, resources are the work of R.T. All other statements are not applicable.

Funding: This research received no external funding. 
Acknowledgments: The authors would like to acknowledge for their support Professor Cornelia SchweppeJohannes Gutenburg University Mainz, Mophradat Art Fellow Program 2017-2018, DAAD, The Münchner Kammerspiele, Kammer4You, Miunikh-Damascus team and The Open Border Ensemble performers.

Conflicts of Interest: The authors declare no conflict of interest.

\section{References}

Agha, Ayham. 2017. Interview by Ruba Totah. Theatre Director and Actor, Maxim Gorki Theatre. Personal interview, Berlin, Germany, May 5.

Ali, Shadi. 2017. Interview by Ruba Totah. Freelance Actor and Singer. Personal interview, Munich, Germany, July 3.

Baker, Mona, and Gabriela Saldanha. 2009. Routledge Encyclopedia of Translation Studies. London: Routledge.

Bala, Sruti. 2014. 'Translation Is the Making of a Subject in Reparation': Elfriede Jelineks Response to Fukushima in Kein Licht. Austrian Studies 22: 183-98. [CrossRef]

Bhimji, Fazila. 2015. Collaborations and Performative Agency in Refugee Theatre in Germany. Journal of Immigrant and Refugee Studies 1: 1-23. ISSN 15562948It.

Cassell, Catherine. 2012. Participant Observation. In Essential Guide to Qualitative Methods in Organizational Research. London: SAGE.

Charmaz, Kathy. 2014. Constructing Grounded Theory. Los Angeles: SAGE.

Cox, Emma. 2018. Postcolonial Noncitizenship in Australian Theatre and Performance: Twenty-first-Century Paradigms. In The Bloomsbury Introduction to Postcolonial Writing: New Contexts, New Narratives, New Debates. London: Bloomsbury Academic, pp. 141-57. ISBN 9781474240079.

Dolan, Jill. 2002. Finding Our Feet in the Shoes of (One An) Other: Multiple Character Solo Performers and Utopian Performatives. Modern Drama 45: 495-518. [CrossRef]

Funk, Nanette. 2016. A spectre in Germany: Refugees, a 'welcome culture' and an 'integration politics'. Journal of Global Ethics 12: 289-99. [CrossRef]

Gelfand, Michele J., Virginia Smith Major, Jana L. Raver, Lisa H. Nishii, and Karen O’Brien. 2006. Negotiating Relationally: The Dynamics of the Relational Self in Negotiations. Academy of Management Review 31: 427-51. [CrossRef]

Glause, Jessica. 2018. Interview by Ruba Totah. Theatre Director. Personal interview, Munich, Germany, May 9.

Jäckle, Sebastian, and Pascal D. König. 2017. The dark side of the German 'welcome culture': Investigating the causes behind attacks on refugees in 2015. West European Politics 40: 223-51. [CrossRef]

Jeffers, Alison. 2014. Refugees, Theatre and Crisis: Performing Global Identities. London: Palgrave Macmillan.

Joseph, May, and Jennifer Fink. 1999. Performing Hybridity. Minneapolis: University of Minnesota Press.

Kabeer, Naila. 1999. Resources, Agency, Achievements: Reflections on the Measurement of Women Empowerment. Development and Change 30: 435-64. [CrossRef]

Komurcu, Onur. 2016. Post Migrant Theatre and Cultural Diversity in the Arts: Race, Precarity and Artistic Labour in Berlin. Ph.D. Dissertation, University of London, Goldsmiths, UK.

Malinowski, Bronislaw. 1922. Argonauts of the Western Pacific, 1st ed.London: Routledge \& K. Paul, New York: Dutton E.P.

Mliehi, Rania. 2017. Interview by Ruba Totah. Dramaturg, Schauspieler, Hannover. Personal interview, Hannover, Germany, April 28.

Montouri, Alfonso. 2003. The complexity of improvisation and the improvisation of complexity: Social science, art and creativity. Human Relations 56: 237-55. [CrossRef]

Oosterlynck, Stijn, Maarten Loopmans, Nick Schuermans, Joke Vandenabeele, and Sami Zemni. 2016. Putting Flesh to the Bone: Looking for Solidarity in Diversity, Here and Now. Ethnic and Racial Studies 39: 764-82. [CrossRef]

Petersen, Anne Ring, and Moritz Schramm. 2017. (Post-)Migration in the Age of Globalisation: New Challenges to Imagination and Representation. Journal of Aesthetics \& Culture 9: 1-12. [CrossRef]

Sharifi, Azadeh. 2016. Theater and Migration. In Independent Theatre in Contemporary Europe: Structures-AestheticsCultural Policy. Bielefeld: Transcript.

Simmel, Georges, ed. 1999. Domination et subordination. In Sociologie. Etudes sur les formes de la socialization. Paris: PUF, pp. 161-265. First published 1908. 
Spencer, Stephen. 2016. Race and Ethnicity: Culture, Identity and Representation. Abingdon: Routledge. Spivak, Gayatri Chakravorty. 2009. Outside in the Teaching Machine. New York: Routledge.

Wilmer, Stephen E. 2018. Performing Statelessness in Europe. Cham: Palgrave Macmillan.

Woolley, Agnes. 2017. Narrating the Asylum Story: Between Literary and Legal Storytelling. Interventions 19: 376-94. [CrossRef] 